\title{
A SISTEMATIZAÇÃO DE PRECEDENTES ÉM MATÉRIA TRIBUTÁRIA
}

\author{
Andréa Mascitto
}

\section{INTRODUÇÃO}

\subsection{A sobrecarga do poder judiciário brasileiro}

Já de muito observamos o afogamento do poder judiciário brasileiro com um infindável número de processos para julgar. Chega-se a duvidar que esse estoque de processos possa um dia ser administrado, até porque é renovado e aumentado pelas milhares de demandas que surgem diariamente.

O modelo brasileiro prestigia o devido processo legal e a ampla defesa, oportunizando que as demandas passem pelas diversas "esferas de revisão" mediante o esgotamento das oportunidades recursais, de modo que os tribunais superiores brasileiros também estão sobrecarregados, não sendo esta uma característica exclusiva das instâncias originárias. Porém, até pela proporção do número de magistrados, é evidente que a ideia não é que cada processo individual passe por uma profunda revisão dos poucos ministros que compõem cada tribunal superior, ${ }^{1}$ mas, mesmo assim, fato é que atualmente esses tribunais julgam um número de casos substancialmente maior que qualquer outra corte superior.

1 O Supremo Tribunal Federal conta com 11 ministros, e o Superior Tribunal de Justiça, com 33, os quais se dedicam inclusive a atividades outras, como por exemplo no Tribunal Superior Eleitoral. 
A título comparativo, confira-se o volume de casos julgados pelos tribunais constitucionais do Brasil, da Espanha e dos Estados Unidos em 2013:²

Número de casos julgados pelo Tribunal Constitucional

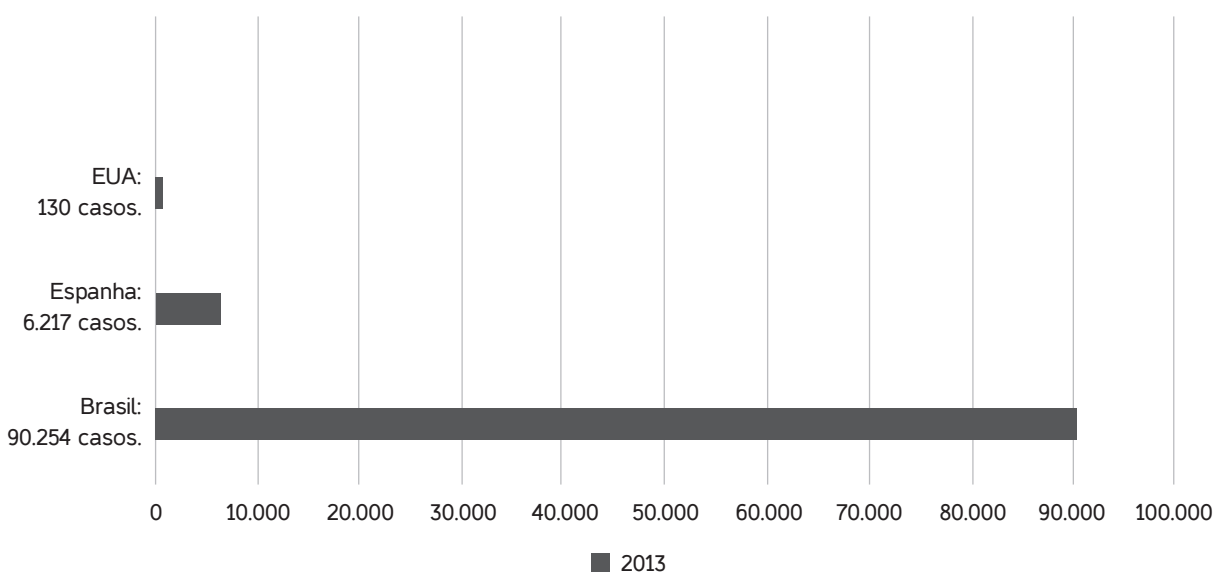

A diferença no número de casos julgados é bastante significativa em 2013, como se depreende do quadro comparativo, o qual mostra que, enquanto no Brasil foram julgados 90.253 casos, na Espanha esse número cai drasticamente para 6.217, e cai ainda mais nos Estados Unidos, cuja Corte Suprema julgou 130 casos. Tomando-se ainda os anos subsequentes como exemplo, vemos que:

i. 2014: o Supremo Tribunal Federal (STF) julgou 114.391 casos, e o Superior Tribunal de Justiça (STJ), 390.052, ${ }^{3}$ o que significa dizer que os tribunais superiores teriam julgado uma média de 1.400 processos por dia caso tivessem trabalho todos os 365 dias do ano, sem finais de semana, feriados, datas festivas etc.

2 http://www.stf.jus.br/portal/cms/verTexto.asp?servico=estatistica\&pagina=decisoesgeral STF: $<$ http://www.stf.jus.br/portal/cms/verTexto.asp?servico=estatistica\&pagina=decisoesgeral>. Acesso em: 31 out. 2018. Suprema Corte Americana: <http://www.uscourts.gov/about-federal-courts/ educational-resources/about-educational-outreach/activity-resources/about>. Acesso em: 31 out. 2018. Tribunal Constitucional da Espanha: <http://www.tribunalconstitucional.es/es/tribunal/memorias/Documents/Estadisticas2013.pdf>.

3 Disponivel em: <http://www.st.jus.br/webstj/Processo/Boletim/verpagina.asp?vPag=0\&vSeq=250>. Acesso em: 31 out. 2018. 
ii. 2015: o STF julgou 116.674 casos, e o STJ, $461.490,{ }^{4}$ o que significa dizer que os tribunais superiores teriam julgado uma média de 1.590 processos por dia caso tivessem trabalho todos os dias do ano.

iii. 2016: o STF julgou 117.486 casos, e o STJ, 470.722, ${ }^{5}$ o que significa dizer que os tribunais superiores teriam julgado uma média de 1.611 processos por dia caso tivessem trabalho todos os dias do ano.

iv. 2017: o STF julgou 126.535 casos, e o STJ, $490.473,{ }^{6}$ o que significa dizer que os tribunais superiores teriam julgado uma média de 1.690 processos por dia caso tivessem trabalho todos os dias do ano.

Trata-se de um número que claramente inviabiliza uma análise profunda caso a caso, preocupando-se mais com o cumprimento de metas numéricas. Ainda, se considerarmos que alguns temas demandam, e de fato merecem, uma discussão mais ampla por atingirem um número maior de pessoas, o sistema se mostra inviável da forma como estruturado originalmente.

\subsection{Inspiração vinda da common law}

Nesse contexto, o poder legislativo começou a explorar alternativas para conter esse grave problema enfrentado pelo judiciário, inspirando-se principalmente no modelo da common law, como é o caso dos Estados Unidos.

O sistema judiciário da common law tem por característica o enaltecimento da jurisprudência como fonte primária do direito, isto é, as decisões pretéritas em casos análogos influenciam fortemente o julgamento de novos casos. Nesse sistema, a chamada "cultura dos precedentes" prevalece e a racionalidade dos julgamentos anteriores é o que precipuamente fundamenta os novos julgamentos. Trata-se de um modelo de origem anglo-saxônica utilizado em Inglaterra, Canadá, Austrália, entre outros. Diferencia-se, portanto, do nosso modelo de origem, a civil law, que se norteia pelo texto da lei (que é a fonte primária do direito). Busca-se compreender como aquele fato sob julgamento se subsome à norma aplicável na

4 Disponivel em: <http://www.stj.jus.br/webstj/Processo/Boletim/verpagina.asp?vPag=0\&vSeq=263>. Acesso em: 31 out. 2018.

5 Disponivel em: <http://www.stj.jus.br/webstj/Processo/Boletim/verpagina.asp?vPag=0\&vSeq=292>. Acesso em: 31 out. 2018.

6 Disponivel em: <http://www.stj.jus.br/webstj/Processo/Boletim/verpagina.asp?vPag=0\&vSeq=301>. Acesso em: 31 out. 2018. 
situação específica (caso a caso), sendo relativizada a força da interpretação em casos anteriores análogos.

A grande vantagem enxergada no sistema da common law para enfrentar o problema da sobrecarga do judiciário brasileiro é que ele estabelece uma prática de aplicação reiterada de precedentes, partindo-se de uma racionalidade comum aplicável a diferentes casos. Com isso, dispensa-se - em princípio e adotadas as cautelas que serão tratadas neste texto - a necessidade de uma profunda e renovada discussão caso a caso, atribuindo um enorme ganho de eficiência ao sistema judiciário.

Essa vantagem é ainda mais clara quando se trata de matéria tributária, já que as disputas tributárias costumam afetar múltiplos contribuintes que discutem uma mesma situação de fato e de direito. ${ }^{7}$ Pensemos, por exemplo, na situação em que milhares de contribuintes recorrem ao judiciário para questionar a constitucionalidade de uma norma instituidora de um tributo que tenha violado o princípio da anterioridade. Basta que se defina se a lei é ou não inconstitucional por violação a esse princípio para que se tenha o condão de solucionar esses milhares de casos sem que sejam individualmente discutidos no STF.

\subsection{Mudanças paulatinamente implementadas pelo poder legislativo}

Vislumbrando essa vantagem, observamos que o poder legislativo começou a implementar mudanças relativas às regras de processo civil brasileiro. ${ }^{8} \mathrm{~A}$ título ilustrativo, e partindo para uma sucinta digressão histórica, devemos lembrar que:

i. O Código de Processo Civil de 1973 (CPC/73) contemplava - com alterações recebidas inclusive em 2001 pela Lei n. 10.352 e em 2006 pelas Lei n. 11.276 e n. 11.277 - incidentes de uniformização de jurisprudência e "assentos vinculantes", a exemplo do quanto prescrito nos art. 285-A; 475,

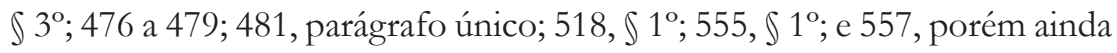
de forma tímida e sem a pretensão dos institutos atuais de amplificação dos efeitos de uma decisão judicial.

7 Tal impressão foi confirmada em estudo realizado pela da Sociedade Brasileira de Direto Público (SBDP): SUNDFELD, Carlos Ari; SOUZA, Rodrigo Pagani de (Coord.). Repercussão Geral e o sistema brasileiro de precedentes. 2010.

8 A presente avaliação está centrada no controle difuso de constitucionalidade e legalidade, e não no controle concentrado. 
ii. Em 2004, com a edição da Emenda Constitucional n. 45, dois institutos de extrema importância foram criados, a saber: súmula vinculante e repercussão geral, que visavam justamente ao efeito multiplicador das decisões do STF (art. 102, \ $3^{\circ}$, da Constituição Federal). Tratou-se de um avanço na direção de que ora tratamos.

iii. Em 2006, com a edição da Lei n. 11.418, acrescentaram-se os art. 543-A e 543-B ao CPC/73, vigente à época, a fim de regulamentar o requisito da repercussão geral e seus efeitos.

iv. Em 2008, com a edição da Lei n. 11.672, acrescentou-se o artigo 543-C ao $\mathrm{CPC} / 73$, vigente à época, criando a figura do recurso repetitivo no âmbito do STJ e regulando seus efeitos.

Todos esses mecanismos já apontavam na direção de buscar a atribuição de maior eficiência ao poder judiciário brasileiro.

\section{CENÁRIO E NOVIDADES NO NCPC}

Exatamente nesse contexto é que a Lei n. 13.105 (Novo Código de Processo Civil - NCPC) foi editada, em 16 de março de 2015. Prestigiando o esforço iniciado anos antes pelo poder legislativo, o NCPC enalteceu e sistematizou a "cultura dos precedentes", principalmente (mas não exaustivamente) pela manutenção e pelo reforço dos institutos da repercussão geral e dos recursos repetitivos, bem como pela criação do chamado Incidente de Resolução de Demanda Repetitiva (IRDR), tratado nos art. 976 a 987, prevendo oportunidades de se recorrer diretamente ao tribunal (art. 988, NCPC) nas hipóteses em que os precedentes se mostrarem descumpridos.

No mais, o NCPC cria todo um ambiente de favorecimento à sistematização de precedentes ao:

i. reforçar a necessidade de fundamentação das decisões judiciais e, nesse tocante, destacar que a falta de justificativa para que um precedente aplicável ao caso concreto não seja observado é causa de oposição de embargos de declaração por omissão (art. 1.022, parágrafo único, inciso I), bem como que a mera menção ao precedente ou súmula não é suficiente para que se tenha a decisão por devidamente fundamentada (art. $489, \mathbb{S} 1^{\circ}$, incisos IV e V);

ii. reforçar a necessidade de os tribunais cuidarem de uniformização, estabilidade, integridade e coerência de suas decisões (art. 926); 
iii. sistematizar a vinculação de juízes e tribunais às decisões em controle concentrado, súmulas vinculantes, incidentes de competência ou resolução de demandas repetitivas, súmulas do STF e do STJ em geral, e orientação do plenário ou órgão especial a que vinculados, aproximando-os ao sistema da common law em que os precedentes são fonte primária do direito (art. 927);

iv. criar procedimentos de audiências públicas, possibilidade de modulação e outros mecanismos protetivos da segurança jurídica mesmo em caso de mudança de precedentes (art. 927);

v. atribuir novos contornos ao incidente de assunção de competência ampliando seu espectro, vez que agora cabível em qualquer recurso, remessa necessária ou causas de competência originária (art. 947);

vi. fortalecer o instituto da reclamação e criar o IRDR, como mencionamos anteriormente.

Cabe mencionar rapidamente que o IRDR foi uma das novidades mais significativas trazidas pelo NCPC. Tal incidente pode ser invocado pelas partes, pelo Ministério Público, pela defensoria e também pelo próprio magistrado de primeiro grau ou relator quando identificar efetiva repetição de processos que contenham controvérsia sobre a mesma questão unicamente de direito (questão jurídica e não fática) e houver risco de ofensa à isonomia e à segurança jurídica. Ele suspende os demais casos iguais em curso na região circunscrita ${ }^{9}$ e será resolvido pelo órgão colegiado do tribunal local (de segunda instância) competente, ${ }^{10}$ não se aplicando quando os tribunais superiores já estiverem examinando o assunto em caráter repetitivo. Nota-se que há um claro fortalecimento do papel dos tribunais de segunda instância, deixando de ser vistos como um mero "tribunal de passagem".

São exemplos de pedidos de instauração de IRDR em matéria tributária:

i. TRF da $1^{\text {a }}$ Região: necessidade de se declararem suspeitos ou impedidos os auditores fiscais atuantes como conselheiros no Conselho Administrativo de Recursos Fiscais (CARF) em razão do conflito de interesses decorrente do pagamento de bônus de produtividade (Medida Provisória n. 765). IRDR já julgado e declarada a desnecessidade da medida.

ii. TRF da $3^{a}$ Região: (i.1) incidência de contribuição ao Programa de Integração Social (PIS) e Contribuição para o Financiamento da Seguridade

9 Podendo, a pedido, o STF/STJ estender a suspensão a todo o território nacional até julgamento de Recurso Especial ou Extraordinário que ataque a decisão do IRDR.

10 A ser definido pelo próprio tribunal. Exemplo: TJ/SP, Portaria n. 05/2016, Turma Especial na Seção de Direito Público para julgar IRDR e assunção de competência. 
Social (Cofins) sobre receitas financeiras em razão da edição do Decreto n. 8.426/2015; (i.2) necessidade de instauração de incidente de desconsideração da personalizada jurídica para o redirecionamento de execução de crédito tributário da pessoa jurídica para os sócios (em vez de pedido nos autos da própria execução fiscal).

iii. TRF da $4^{a}$ Região: interpretação do art. 158, inciso I, da Constituição Federal, no âmbito da distribuição das receitas arrecadadas a título de Imposto de Renda Retido na Fonte (IRRF), incidente sobre valores pagos pelos municípios, a qualquer título, a pessoas físicas ou jurídicas contratadas para prestação de bens ou serviços.

iv. TRF da $5^{a}$ Região: aplicabilidade do incidente de desconsideração da personalidade jurídica em sede de execução fiscal.

v. Tribunal de Justiça do Rio de Janeiro: limite (valorativo) para ajuizamento de execução fiscal.

O IRDR e todos os institutos e mecanismos sucintamente listados neste capítulo colaboram para a uniformização da jurisprudência e para que a "cultura de precedentes" seja trasladada para o direito brasileiro.

\section{A SISTEMATIZAÇÃO DE PRECEDENTES}

Conforme alertado nos itens anteriores, embora a "cultura dos precedentes" possa apresentar muitas vantagens, ela deve ser implantada com cuidado no Brasil, país que até então observava puramente a civil law e tem passado a buscar soluções bebendo na fonte da common law. É como se quiséssemos encaixar um quadrado em uma bola: deverá haver ajustes e também um grande esforço coletivo (do legislativo, do judiciário e dos jurisdicionados) para que haja sucesso nessa empreitada.

Repise-se: embora o legislativo seja o poder que norteia inicialmente esse novo sistema, será justamente na prática do judiciário que observaremos seu sucesso ou seu fracasso.

\subsection{Requisitos para a bem-sucedida sistematização de precedentes}

Há necessariamente de se sistematizar os precedentes e, para tanto, é indispensável que seja construído um sólido e uniforme repertório de jurisprudência, ${ }^{11}$

11 Art. 926, NCPC: "os tribunais devem uniformizar sua jurisprudência e mantê-la estável, integra e coerente". 
com clareza no contorno do objeto jurídico sob julgamento, eficiente seleção dos recursos representativos da controvérsia e ampla divulgação tanto da eleição do objeto a ser definido pelo sistema de precedentes quanto do resultado da decisão e do entendimento jurídico firmado sobre o tema.

De outro lado, também é indispensável que haja um criterioso exame do caso para que fique clara a identidade do objeto em discussão com o precedente a ser aplicado, ${ }^{12}$ sendo ressalvadas e devidamente identificadas quaisquer nuances que escapem da discussão comum ao tema central (por exemplo, medida judicial que discuta a constitucionalidade de um tributo, sendo necessário que também haja questionamento sobre a decadência do direito fazendário à constituição da dívida).

É interessante observar, nesse sentido, o resultado do estudo Repercussão Geral e o sistema brasileiro de precedentes, realizado em 2010 pela Sociedade Brasileira de Direto Público (SBDP), sob a coordenação de Carlos Ari Sundfeld e Rodrigo Pagani de Souza, no qual se apontam algumas "práticas deficientes" na aplicação de precedentes (reunidas em cinco grupos), que podem figurar como valioso balizador para a implementação do sistema de precedentes, contando inclusive com "dicas" daquilo que, na visão do grupo, poderia ser um roteiro para aperfeiçoar o adequado efeito multiplicador das decisões tomadas pelo STF em sede de repercussão geral.

Todos esses cuidados têm por objetivo preservar e garantir a segurança jurídica e a isonomia como valores maiores a serem protegidos na aplicação dos precedentes. E aqui cabe destacar um grande ponto de atenção: não se trata propriamente de engessar o sistema e os julgados para preservar esses valores maiores, até porque a sociedade evolui e é salutar que o direito com ela evolua, mas, acima de tudo, de o sistema de precedentes prever (e adotar na prática) mecanismos e técnicas para eventual alteração de jurisprudência e também regular os efeitos da revogação de precedentes.

12 "A identificação da questão constitucional discutida nos recursos extraordinários é central no funcionamento do instituto da repercussão geral. Ao definir a questão debatida como constitucional ou infraconstitucional, o STF possibilita que os tribunais de origem identifiquem e sobrestem recursos que versem sobre a mesma questão, bem como norteia as partes que tenham litígios sobre o mesmo tema e a sociedade de um modo geral acerca do entendimento do Tribunal sobre a matéria. Dessa maneira, ao descrever a questão constitucional, o STF facilita às partes e às instâncias do Judiciário uma aplicação uniforme do instituto da repercussão geral” (SUNDFELD, Carlos Ari; SOUZA, Rodrigo Pagani de (Coord.). Repercussão Geral e o sistema brasileiro de precedentes. 2010. p. 10). 


\subsection{Mecanismos e técnicas para eventual alteração de jurisprudência}

No direito norte-americano, por exemplo - enquanto ilustração clara do common law "relativista moderno" $-{ }^{13}$ existem diversas técnicas para alteração de jurisprudência, como overruling, overriding, transformation, drawing of inconsistent decisions etc. Cada uma com suas nuances (e também rígidas delimitações de competência), ${ }^{14}$ tais técnicas permitem a construção de uma nova compreensão jurídica para aquele dado contexto sob discussão, ou melhor dizendo, uma "reconstrução" da interpretação jurídica. Essa reconstrução pode ser total (revogação do entendimento anterior) ou parcial (apenas restrição àquele entendimento e readaptação da regra), seja por revisão do tema, seja em decorrência de necessária adaptação do sistema a regras novas nele inseridas, evolução do pensamento jurídico ou outro motivo. Não é objetivo deste artigo tratar individualmente de cada técnica, mas alertar sobre sua existência e sua importância, bem como trazer alternativas de inspiração para a construção de um sistema de precedentes no país.

Adicionalmente, e ainda em relação à mudança de paradigmas e precedentes, geram debate os efeitos dessa "ruptura jurisprudencial" no tempo - se retroativos ou prospectivos -, bem como o marco da aplicação prospectiva. Muitos doutrinadores de renome sustentam que a prospectividade é a forma de garantir a segurança jurídica e a confiança no sistema judiciário. Já outros contra-argumentam que a forma prospectiva leva à consolidação de tratamento anti-isonômico e de incoerência sistêmica. Isso não é propriamente uma novidade no Brasil: a modulação já vem sendo aqui discutida há alguns anos, em especial diante da crítica aos tribunais superiores quanto à mudança de entendimento sobre diversos temas. ${ }^{15}$

Independentemente dos debates surgidos, fato é que tais técnicas devem ser previstas e aplicadas pelo poder judiciário em prol, mais uma vez, da construção bem-sucedida do sistema brasileiro de precedentes. Por isso, volta-se a destacar a importância de se prever e debater com afinco, no direito brasileiro, institutos como a modulação (esclarecendo efetivamente seus contornos e limites), a teoria

13 Usamos tal designação em contraponto à common law anglo-saxônica, cuja tradição enrijecia a cultura de precedentes.

14 Via de regra reservada à corte superior.

15 A título meramente ilustrativo, citamos a tributação das sociedades de advogados pela Cofins, isenção de Imposto sobre Produtos Industrializados (IPI) etc. 
do distinguish, ${ }^{16}$ a teoria da transcendência dos motivos determinantes, e a reclamação, sem prejuízos à criação de novos institutos que se mostrem necessários com a evolução do sistema no tempo. Vê-se que, em determinada medida, o NCPC cuidou de plantar essas "sementes", que deverão florescer a partir do debate acadêmico e pragmático do direito.

Justamente apontando na direção de mudança jurisprudencial versus segurança jurídica $v s$. coerência sistêmica $v s$. confiabilidade no judiciário, vemos hoje um tema importantíssimo afetado à definição pelo STF com repercussão geral reconhecida,${ }^{17}$ que é a delimitação do limite da coisa julgada em âmbito tributário na hipótese de o contribuinte se beneficiar de decisão judicial declaratória da inexistência de relação jurídico-tributária transitada em julgado pautada em inconstitucionalidade do tributo que, posteriormente, veio a ser declarado constitucional pelo STF em controle concentrado e abstrato de constitucionalidade. Vê-se no foco do debate, portanto, a possibilidade de relativização da coisa julgada na seara tributária "em decorrência da superveniência de novos parâmetros normativos ou de decisão do Supremo Tribunal Federal que considere constitucional o diploma normativo tido por inconstitucional pela decisão passada em julgado". ${ }^{18}$

\section{CONSIDERAÇÕES FINAIS}

Em apertada síntese, vimos que:

i. A sobrecarga do poder judiciário brasileiro, em especial dos tribunais superiores, fez com que o direito brasileiro olhasse para o modelo implementado em outros países e se inspirasse nas vantagens do sistema da common law, no qual a jurisprudência figura como fonte primária do direito.

ii. A partir daí, o poder legislativo passou a introduzir institutos e mecanismos no direito brasileiro (como a súmula vinculante, a repercussão geral e os

16 Distinguishing é o mecanismo de diferenciação de um dado caso em relação à questão sedimentada em precedente. Ele permite que se justifique a inaplicabilidade de um precedente a um determinado caso dadas as suas peculiaridades, que denotem ausência de convergência entre os fatos relevantes (material facts) e a conformação da fundamentação (substantive rationale) utilizada no caso predecessor àquele caso.

17 Repercussão Geral no RE n. 949.297/CE.

18 Trecho da manifestação do ministro Edson Fachin, de 4 de março de 2016, em plenário virtual para reconhecimento de repercussão geral. Disponivel em: <http://www.stf.jus.br/portal/jurisprudenciaRepercussao/verPronunciamento.asp?pronunciamento=6189314)>. Acesso em: 27 nov. 2018. 
recursos repetitivos, aliados aos incidentes de uniformização de jurisprudência e "assentos vinculantes") visando atribuir maior eficiência ao poder judiciário brasileiro.

iii. O NCPC foi editado nesse contexto, em 2015, e preocupou-se em criar todo um ambiente de favorecimento à sistematização de precedentes que ilustramos no corpo deste artigo.

iv. O sistema de precedentes possui nobre missão que extravasa o interesse na celeridade processual e no desafogamento do judiciário, estando fortemente ligado ao enaltecimento da segurança jurídica, da confiabilidade no poder judicante e da isonomia, que são valores importantíssimos para o ordenamento brasileiro.

Do exposto, e dado que o direito brasileiro ainda engatinha na chamada "cultura de precedentes", recomenda-se cautela em sua implantação no país até para que de fato atinja a sua nobre missão e não ceda espaço da discussão jurídica à discussão política.

As cautelas dizem respeito ao momento da criação das regras, mas principalmente à sistematização dos precedentes, isto é, à formação dos precedentes e à sua aplicação (ou inaplicação), revisão, revogação etc. Por isso, sugere-se a análise das técnicas e dos mecanismos extraídos do direito comparado e sua ampla discussão para adaptação à realidade brasileira, sendo certo que a atual discussão pendente no STF sobre o limite da coisa julgada em âmbito tributário (RE n. 949.297/CE) tem muito a colaborar com o tema já que tangencia questões de fundo importantes como mudança jurisprudencial versus segurança jurídica versus coerência sistêmica versus confiabilidade no judiciário.

Embora a questão diga eminentemente respeito a um embate entre o sistema de controle de constitucionalidade difuso versus concentrado, ela demanda profunda reflexão sobre a coerência sistêmica da construção jurisprudencial e eventuais mudanças de entendimento no percurso, caracterizando-se como uma excelente oportunidade para que toda a comunidade jurídica exercite a ampla dialeticidade demandada para a construção de um sistema de precedentes robusto no Brasil. 
